\title{
Flora do Espírito Santo: Micropholis (Sapotaceae-Chrysophylloideae) ${ }^{1}$
}

\author{
Flora of the Espírito Santo: Micropholis (Sapotaceae-Chrysophylloideae)
}

\author{
Wenia de Oliveira Souza ${ }^{2,3}$ \& Anderson Alves-Araújo ${ }^{2}$
}

\begin{abstract}
Resumo
Neste trabalho são apresentados dados morfológicos, informações sobre distribuição geográfica e estado de conservação para as espécies do gênero Micropholis (Sapotaceae) nativas do Espírito Santo. Um total de cinco espécies de Micropholis foi encontrado: M. compta, M. crassipedicellata, M. gardneriana, M. guyanensis subsp. guyanensis e M. venulosa. Este número representa 100\% das espécies ocorrentes na Mata Atlântica. Os caracteres mais importantes para a distinção das espécies são: nervura central sulcada ou não na face adaxial, nervuras secundárias espaçadas ou congestas entre si distinguíveis ou indistinguíveis das terciárias, indumento dos ramos jovens e forma da folha. Micropholis gardneriana constitui um novo registro para o Espírito Santo e Micropholis compta foi categorizada como Quase Ameaçada (NT).
\end{abstract}

Palavras-chave: Ericales, Mata Atlântica, neotrópicos, taxonomia.

\begin{abstract}
Herein, we provide information about morphological data, geographic distribution and conservation status for native species of Micropholis from Espírito Santo state (ES), Brazil. A total of five species were found: M. compta, M. crassipedicellata, M. gardneriana, M. guyanensis subsp. guyanensis, and M. venulosa. They represent $100 \%$ of the known species of Micropholis from the Brazilian Atlantic rainforest. The most important characters for distinguishing the species are: type and color of indument on the young branches, leaf shape, midrib sunken or not on the upper leaf surface, distinguishable secondary veins from the tertiary ones. Micropholis gardneriana constitutes a new record for the Espírito Santo state. Amongst Micropholis species from ES, only Micropholis compta is considered as Near Threatened (NT).
\end{abstract}

Key words: Ericales, Atlantic rainforest, neotropics, taxonomy.

\section{Introdução}

O Brasil possui atualmente ca. de 33.000 espécies nativas de Angiospermas registradas com maior número encontrado no Domínio da Mata Atlântica representando ca. de 15.500 táxons, dos quais cerca de 8.700 são endêmicos (BFG 2015).

O Espírito Santo ocupa o sétimo lugar dentre os estados brasileiros mais ricos em Angiospermas com aproximadamente $32 \%$ das espécies nativas da Mata Atlântica e 516 espécies endêmicas (Dutra et al. 2015). E segundo Garbin et al. (2017), ainda existe uma grande lacuna de conhecimento sobre a vegetação do Espírito Santo.
Dentre os grupos taxonômicos de extrema relevância para os ambientes florestais, pode-se destacar os representantes da família Sapotaceae que são ecologicamente importantes na manutenção da fauna frugívora, por apresentar frutos com polpa e sabor adocicado, atraindo uma grande variedade de dispersores como morcegos, aves e até roedores (Pennington 1990, 1991, 2004).

Sapotaceae possui 58 gêneros e cerca de 1.250 espécies, apresenta distribuição pantropical e é representada, principalmente, por táxons arbóreos e arbustivos, raramente arbustos geoxílicos (Pennington 1990, 1991). É reconhecida

\footnotetext{
${ }^{1}$ Parte da dissertação de Mestrado do primeiro autor.

${ }^{2}$ Universidade Federal do Espírito Santo - UFES/CEUNES, Prog. Pós-graduação em Biodiversidade Tropical - PPGBT, Rod. BR-101 Norte, Km 60, Litorâneo, 29932-900, São Mateus, ES, Brasil.

${ }^{3}$ Autor para correspondência: weniaoliveirasouza@gmail.com
} 
principalmente por sua latescência, folhas geralmente alternas, corola gamopétala e ovário súpero (Pennington 1990, 1991). Atualmente está dividida em três subfamílias: Sarcospermatoideae, Sapotoideae e Chrysophylloideae (Swenson \& Anderberg 2005). Nos Neotrópicos, 12 gêneros e cerca de 450 espécies são registrados e estão predominantemente distribuídos em florestas úmidas de baixas altitudes, embora alguns gêneros sejam bem representados nas savanas de altitude da Guiana (Ecclinusa Mart.) e em zonas semi-áridas da América Central e Antilhas (Sideroxylon L.) (Pennington 1990).

No Brasil, a grande maioria das espécies está registrada para a Floresta Amazônica, porém outro importante centro de distribuição é a Mata Atlântica com número expressivo de táxons (BFG 2015). Dados recentes apontam o registro de 12 gêneros e 232 espécies ocorrentes no Brasil, dentre os quais Pouteria Aubl. é o mais rico com 122 spp., seguido de Chrysophyllum L. com 31 spp., Micropholis (Griseb.) Pierre com 29 spp., Pradosia Liais com 17 spp. e Manilkara Adans. com 16 spp., distribuídas entre os estados brasileiros (BFG 2015).

Micropholis (Griseb.) Pierre (Chrysophylloideae) têm se destacado como um grupo natural (Swenson et al. 2008) e pode ser diferenciado dos demais gêneros por apresentar nervuras secundárias estreitamente paralelas, muitas vezes não diferenciadas das nervuras terciárias, geralmente com aparência estriada, flores com corola campanulada, o tubo quase sempre excedendo os lobos raramente igualando-os, lobos da corola inteiros, estames inclusos ou exsertos e presença de estaminódios (Pennington 1990).

Este gênero é exclusivamente neotropical com 38 espécies distribuídas nas Américas Central e do Sul e Caribe. No Brasil são registradas 29 espécies, dentre as quais 10 são consideradas endêmicas e cinco ocorrem na Mata Mata Atlântica $(M$. compta, $M$. crassipedicellata, $M$. gardneriana, $M$. guyanensis e $M$. venulosa), sendo duas exclusivas deste bioma ( $M$. compta e M. crassipedicellata) (Pennington 1990; BFG 2015).

Morfologicamente, Micropholis é facilmente reconhecido e está representado em umas das principais obras taxonômicas para a família nos neotrópicos (e.g., Pennington 1990), porém caracteres inconsistentes para delimitação interespecífica indicam a necessidade de análises mais detalhadas.

Considerando os problemas de determinação específica de Micropholis devido aos tênues limites morfológicos e, consequentemente, pouco evidentes, o presente trabalho teve por objetivo realizar o tratamento taxonômico das espécies de Micropholis nativas do Espírito Santo. Os resultados dessa pesquisa são parte integrante do Projeto Flora do Espírito Santo e fornecem dados morfológicos, distribuição geográfica e estados de conservação.

\section{Material e Métodos}

Expedições de coleta foram realizadas de março/2015 a maio/2016 em 11 Unidades de Conservação e duas áreas particulares, abrangendo as diferentes fitofisionomias ao longo da área de estudo (Tab. 1). O material obtido foi herborizado de acordo com os métodos usuais em taxonomia vegetal (Bridson \& Forman 1998). Os vouchers foram depositados no Herbário VIES e duplicatas enviadas aos Herbários CVRD e RB (Thiers, continuamente atualizado).

Espécimes de Micropholis das principais coleções do estado foram analisados (CVRD, MBML, VIES e SAMES), além de consultas às coleções online (acrônimos de acordo com Thiers, continuamente atualizado). Amostras de flores/frutos foram mantidas em álcool 70\% para posterior identificação, descrições e ilustrações dos táxons.

Para identificação foram consultadas bibliografias especializadas (Pennington 1990, 2006; Silva 2004; Terra-Araújo et al. 2012), vouchers, tipos nomenclaturais e descrições originais.

As ilustrações foram confeccionadas com auxílio de um estereomicroscópio e incluíram as partes vegetativas e reprodutivas, baseando-se em materiais herborizados e/ou fixados em álcool 70\%. Quando necessário, as descrições taxonômicas foram complementadas a partir das análises de material adicional e/ou bibliografias especializadas (Pennington 1990). A terminologia utilizada nas descrições morfológicas foi baseada em Hickey (1973) e Harris \& Harris (2001).

As recomendações de categorias de ameaça foram baseadas segundo as Categorias e Critérios da Lista Vermelha da IUCN (2017). A categorização constitui-se da distribuição total de cada táxon, sendo a Extensão de ocorrência (EOO) e a Área de ocupação (AOO) calculadas com o Geospatial Conservation Assesment Tool (GeoCat) (Bachman et al. 2011). Mapas de distribuição geográfica das espécies foram confeccionados no software ArcGis 10.2.2. 
Tabela 1 - Unidades de conservação e propriedades particulares visitadas no estado do Espírito Santo, Brasil. Table 1 - Conservation units and private properties visited in the state of Espírito Santo, Brazil.

\begin{tabular}{ll}
\hline Locais de coleta & Localidade \\
\hline APA da Pedra do Elefante & Nova Venécia-ES \\
Estação Biológica Santa Lúcia & Santa Teresa-ES \\
Monumento Natural dos Pontões Capixabas & Pancas-ES \\
Parque Estadual de Forno Grande & Castelo-ES \\
Parque Estadual de Itaúnas & Conceição da Barra-ES \\
Parque Estadual de Mata das Flores & Castelo-ES \\
Parque Estadual Paulo César Vinha & Guarapari-ES \\
Parque Nacional de Caparaó & Serra do Caparaó-ES/MG \\
Rebio de Sooretama & Linhares-ES \\
Rebio do Córrego do Veado & Pinheiros-ES \\
Reserva Natural Vale & Linhares-ES \\
Afloramento da Torre & Água Doce do Norte-ES \\
Mata CEUNES/UFES* & São Mateus-ES \\
\hline$*=$ áreas particulares & \\
\hline particular areas &
\end{tabular}

\section{Resultados e Discussão}

No Espírito Santo foram reconhecidas cinco espécies de Micropholis: M. compta Pierre in Urb., M. crassipedicellata (Mart. \& Eich.) Pierre, M. gardneriana (A. DC.) Pierre, M. guyanensis (A. DC.) Pierre subsp. guyanensis e M. venulosa (Mart. \& Eichler) Pierre. As demais espécies citadas e identificadas nas coleções biológicas com ocorrência para o estado, como $M$. cuneata Pierre ex Glaz. e M. gnaphaloclados (Mart.) Pierre foram equivocadamente determinadas e corrigidas durante a realização desse trabalho.

Micropholis cuneata é atualmente considerada sinônimo heterotípico de Micropholis crassipedicellata (Mart. \& Eich.) Pierre e, além disso, as amostras D.A. Folli 108, 2178 (ambas no CVRD) são na verdade exemplares de Diploon cuspidatum (Hoehne) Cronquist, que diferem do gênero Micropholis, principalmente pela ausência de estaminódios, ovário glabro e unilocular. Da mesma forma, as amostras D.A. Folli 298, 597, 1244, 5882 (CVRD) determinadas como Micropholis gnaphaloclados (Mart.) Pierre, tratam-se na verdade de um novo táxon do gênero Sideroxylon (Souza et al., dados não publicados).

Os caracteres morfológicos vegetativos mais úteis para a distinção específica estão nas nervuras centrais na face adaxial foliar (sulcadas ou não), nervuras secundárias (espaçadas ou muitos próximas; distinguíveis ou indistinguíveis das terciárias), espaçamento entre nervuras coletora $\mathrm{e}$ marginal (quase fusionadas ou distintas) e formas das folhas. Já os reprodutivos estão na margem das sépalas (ciliadas ou não), nos estigmas (simples ou lobados), estiletes (costados ou não) e no tamanho das flores.

Todas as espécies podem ser encontradas nas matas de tabuleiros e matas de encosta, porém Micropholis venulosa e M. gardneriana também podem ser encontradas em restingas e matas de altitude, respectivamente. Além disso, de acordo com BFG (2015), M. gardneriana constitui um novo registro para a Flora do ES.

Micropholis compta e M. crassipedicellata são as únicas consideradas endêmicas do Brasil e de ocorrência conhecida apenas para a Mata Atlântica. As demais espécies podem ser encontradas nos Domínios da Mata Atlântica, da Amazônia, da Caatinga e do Cerrado. Além disso, as cinco espécies encontradas no Espírito Santo representam todas às citadas com ocorrência para a Mata Atlântica.

Micropholis crassipedicellata foi a única espécie com nome popular identificado, sendo chamada de Curubixá (ES). Não foi encontrada nenhuma informação sobre nome popular para os outros táxons com ocorrência para o Espírito Santo. 
Estado de conservação: Micropholis compta foi a única espécie categorizada como quase ameaçada (NT) (CNCFlora 2017), as demais espécies ocorrentes no ES, não se enquadram nos padrões para espécies ameaçadas, sendo desta forma categorizadas como Pouco preocupante (LC).

\section{Tratamento taxonômico}

Micropholis (Grisebach) Pierre, Not. bot. 37. 1891.

Árvores até $29 \mathrm{~m}$ alt. Ramos jovens pubescentes, pubérulos ou estrigosos, tricomas malpiguiáceos, lenticelas presentes ou ausentes. Folhas alternas, dísticas ou espiraladas, margem inteira, venação broquidódroma, presença de nervura coletora e marginal, tricomas malpiguiáceos. Fascículos 2-11-floros, axilares (raramente ramifloros). Flores uni a bissexuadas, pediceladas. Sépalas 4-5, persistentes no fruto, presença de tricomas malpiguiáceos na face externa. Corola tubular, 4-5 lobos. Estames 4-5, inclusos, epipétalos, lanceolados, glabros. Estaminódios 4-5, inclusos, epipétalos, petaloides ou não, glabros. Ovário 4-5-locular, súpero, pubescente a piloso, tricomas malpiguiáceos. Frutos bacídios. Semente solitária, superfície lisa, lustrosa, cicatriz rugosa, longitudinal.

\section{Chave de identificação das espécies de Micropholis nativas do Espírito Santo, Brasil}

1. Nervuras secundárias com aspecto estriado, indistinguíveis das terciárias a olho nu em ambas as faces, nervuras coletora e marginal quase fusionadas.

2. Nervura central na face adaxial plana a levemente proeminente, sépalas $\leq 2 \mathrm{~mm}$ compr., pétalas (tubo + lobos) $\leq 1,7 \mathrm{~mm}$ compr...

5. Micropholis venulosa

2'. Nervura central na face adaxial sulcada a levemente sulcada, sépalas $\geq 2,5 \mathrm{~mm}$ compr., pétalas (tubo + lobos) $\geq 3 \mathrm{~mm}$ compr.

3. Fascículos axilares, ovário pubescente 1. Micropholis compta

3'. Fascículos axilares ou ramifloros, ovário piloso 3. Micropholis gardneriana

1'. Nervuras secundárias sem aspecto estriado, distinguíveis das terciárias e ordens superiores a olho nu na face abaxial, nervura coletora presente e distinta da marginal (bem espaçadas).

4. Ramos e pecíolos costados a levemente costados, face foliar abaxial puberulenta, tricomas ferrugíneos, fascículos estipitados, estilete costado, estigma 5-lobado

4. Micropholis guyanensis subsp. guyanensis

4'. Ramos e pecíolos não costados, face foliar abaxial glabrescente a estrigosa quando jovens, tricomas alvos, fascículos não estipitados, estilete não costado, estigma simples

2. Micropholis crassipedicellata

1. Micropholis compta Pierre in Urb., Symb. Antill. 5: 125.1904. Figs. 1a-e; 3; 5e

Árvores até $14 \mathrm{~m}$ alt. Ramos jovens costados, pubescentes, tricomas ferrugíneos, lenticelas ausentes. Folhas 9,7-17 × 2-4,5 cm, oblongas, alterno-espiraladas, discolores, cartáceas, base obtusa, ápice atenuado, acuminado a agudo, face adaxial glabra, face abaxial pubescente ao longo da nervura central, tricomas ferrugíneos; venação broquidódroma, nervura central sulcada a levemente sulcada na face adaxial, nervuras secundárias muito próximas, paralelas entre si com aspecto estriado e indistinguíveis das terciárias e ordens superiores a olho nu em ambas as faces, nervura coletora presente, quase fusionada à nervura marginal, margem plana; pecíolos 4-9 mm compr., canaliculado, não costado, pubescente, não costado, tricomas ferrugíneos.
Fascículos 3-9-floros, axilares, não estipitados. Flores bissexuadas, pedicelos 3-4 mm compr., pubescentes, tricomas dourados. Sépalas 5, 3-4,5 mm compr., suborbiculares a ovadas, ápice agudo a arredondado, face externa levemente pubescente, face interna com tricomas estrigosos. Pétalas 5, tubo ca. $4 \mathrm{~mm}$ compr., lobos ca. 1,5 mm compr., ovadas a arredondados, glabros ou com tricomas estrigosos na face externa dos lobos. Estames 5, filetes $0,5-0,8 \mathrm{~mm}$ compr., anteras $0,75-1 \mathrm{~mm}$ compr. Estaminódios 5, 1-1,25 mm compr., lanceolados, glabros. Ovário 5-locular, 1,5-2 mm compr., ovoide a triangular, pubescente; estilete 1-2 mm compr., glabro; estigma simples, ligeiramente lobado a 5-lobado. Frutos 1-1,5 cm compr., obovoides a elipsoides, glabros na maturidade, amarelos. Sementes não vistas. 

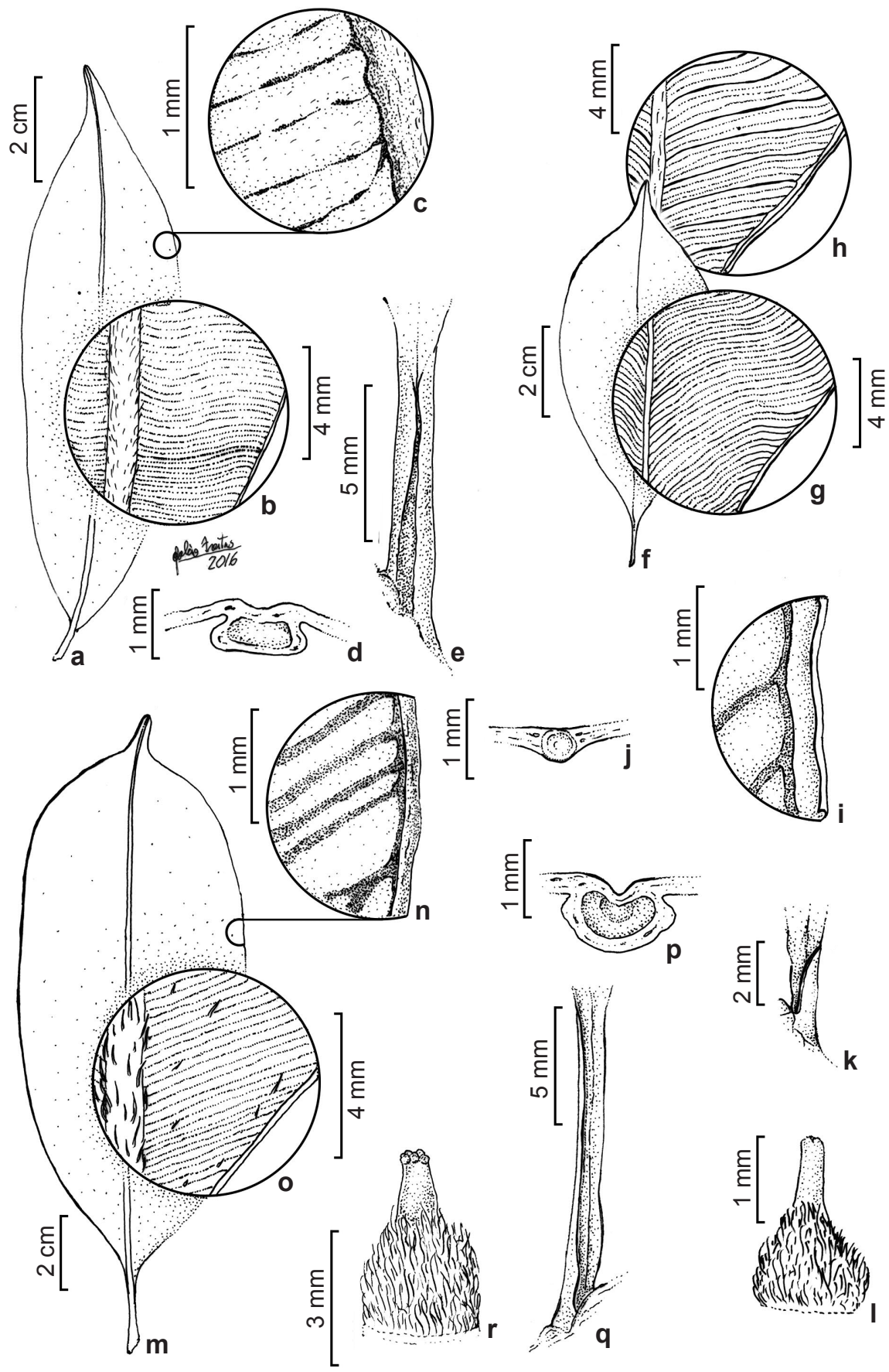

Figura 1 - a-e. Micropholis compta - a. folha; b. detalhe da face adaxial; c. detalhe das nervuras coletora e marginal; d. detalhe da nervura central; e. detalhe do pecíolo. f-1. Micropholis crassipedicellata - f. folha; g. detalhe da face adaxial; h. detalhe da face abaxial; i. detalhe das nervuras coletora e marginal; j. detalhe da nervura central; k. detalhe do pecíolo; 1. ovário. m-r. Micropholis gardneriana - m. folha; $\mathrm{n}$. detalhe das nervuras coletora e marginal; o. detalhe da face adaxial; p. detalhe da nervura central na face adaxial; q. detalhe do pecíolo; r. ovário. (a-e. L.D. Thomaz 1384; f-1. D.A. Folli 60 \& Kollmann 588; m-r. L.D. Thomaz 919 \& D.A. Folli 2184).

Figure 1 - a-e. Micropholis compta - a. leaf; b. upper surface detail; c. detail collecting and marginal veins; d. midrib detail; e. petiole detail. f-1. Micropholis crassipedicellata - f. leaf; g. upper surface detail; h. lower surface detail; i. detail collecting and marginal veins; j. midrib detail; k. petiole detail; 1 . ovary. m-r. Micropholis gardneriana $-\mathrm{m}$. leaf; $\mathrm{n}$. detail collecting and marginal veins; $\mathrm{o}$. upper surface detail; $\mathrm{p}$. detail midrib in upper surface; q. petiole detail; r. ovary. (a-e. L.D. Thomaz 1384; f-1. D.A. Folli 60 \& Kollmann 588; m-r. L.D. Thomaz 919 \& D.A. Folli 2184). 
Material examinado: Santa Teresa, Estação Biológica de Santa Lúcia, 26.VIII.1993, est., L.D. Thomaz 1384 (MBML). Sooretama, Reserva Biológica de Sooretama, 16.XI.2015, est., W.O. Souza 479, 480 (VIES).

É endêmica do Brasil, distribuindo-se exclusivamente no Domínio Mata Atlântica, com ocorrência nas regiões Sudeste e Nordeste (Bahia e Pernambuco) (BFG 2015). No ES é conhecida apenas para ambientes preservados dos Municípios de Santa Teresa e Sooretama (Fig. 3), sendo categorizada como quase ameaçada (NT). Apresenta Floração e Frutificação registradas em Outubro e Abril, respectivamente (Pennington 1990). Dados morfológicos das flores e frutos foram obtidos a partir de descrições disponibilizadas em Pennington (1990) e Alves-Araújo \& Alves (2010).

Micropholis compta pode ser facilmente confundida com $M$. gardneriana, havendo poucos caracteres diagnósticos para distinção específica, dentre eles: as inflorescências ( $M$. compta: fascículos axilares vs. M. gardneriana: fascículos axilares ou ramifloros) e indumento do ovário (M. compta: pubescente vs. M. gardneriana: piloso). Diante da fragilidade dos poucos caracteres morfológicos diagnósticos e os mesmos apresentarem variações tênues, faz-se necessária a análise de um número maior de amostras provenientes de outras localidades para futuras inferências a respeito de prováveis sinonímias.

\section{Micropholis crassipedicellata (Mart. \& Eich.)} Pierre, Not. Bot. 40. 1891.

Figs. 1f-1; 3; 5b

Árvores até $29 \mathrm{~m}$ alt. Ramos jovens não costados, estrigosos, tricomas alvos, lenticelas presentes ou não. Folhas 4,1-10,5 × 2-5 cm, obovadas a oblanceoladas, alterno-espiraladas, discolores, cartáceas, base atenuada, ápice acuminado a atenuado, glabrescente a estrigosa quando jovens nas duas faces, glabras a glabrescentes a glabras quando adulta, tricomas alvos, venação broquidódroma, nervura central plana na face adaxial, nervuras secundárias espaçadas entre si, sem aspecto estriado, indistinguíveis das terciárias e ordens superiores a olho nu na face adaxial, distinguíveis das terciárias e ordens superiores a olho nu na face abaxial, nervura coletora presente, distinta da nervura marginal (bem espaçadas), margem levemente revoluta; pecíolo 3-7 $\mathrm{mm}$ compr., levemente canaliculado, não costado, estrigoso em folhas jovens, glabrescentes a glabros em folhas adultas, tricomas alvos. Fascículos 3-8-floros, axilares, não estipitados. Flores bissexuadas, pedicelo 3-4 mm compr., pubescentes, tricomas dourados. Sépalas 5, 1,2-2 × 1,2-2 mm, ovadas, ápice arredondado a obtuso, pubescente nas duas faces, tricomas dourados, margem ciliada. Pétalas 5, tubo 0,5-1,1 mm compr., lobos 0,9-1,4× 0,6-1,1 mm, ovadas a oblongos, ápice arredondado, glabros. Estames 5, filetes 0,3-0,5 mm compr., anteras 0,4-0,6 mm compr. Estaminódios 5, 1-1,2 mm compr., petaloide, glabros. Ovário 4-5-locular, 1-1,3 mm compr., ovoide, pubescente, tricomas dourados; estilete 1-1,8 mm compr., não costado, glabro; estigma simples. Frutos $2-4,1 \times 1,7-2,5$ $\mathrm{cm}$, globoides a subgloboides, glabros, marrons a enegrecidos. Semente 1,9-2,3 × 1,2-1,6 cm, lisa, lustrosa, castanho, achatada longitudinalmente na cicatriz; cicatriz 1,7-2,2 × 0,5-0,9 cm, fosca.

Material examinado: Águia Branca, Águas Claras, propriedade do Zequinha, 28.XI.2006, fr., L.F.S. Magnago 1598 (MBML). Conceição da Barra, Reserva Biológica do Córrego Grande, 2.II.2012, fl., W.B. Silva \& M. Ribeiro 29 (VIES, SAMES); próximo ao final do transecto 3, 21.VII.2011, fr., M. Ribeiro et al. 584 (VIES). Guaçuí, Floresta do Rosal, parcela 10 n 44, 29.VII.2010, R.A. Curto et al. 107 (VIES). Linhares, Reserva Natural Vale, próximo à estrada, 2.I.1979, fl., D.A. Folli 60 (CVRD, VIES); próximo à estrada, 30.XII.1981, fl., D.A. Folli 355 (CVRD); aceiro do Catelã com o João Pedro, próximo à antiga casa de guarda, 30.XII.1981, fl., D.A. Folli 356 (CVRD, VIES); lado esquerdo da Torre, 29.VII.1991, fr., D.A. Folli 400 (VIES); 29.VIII.1991, fr., D.A. Folli 1400 (CVRD). Pinheiros, Reserva Biológica do Córrego do Veado, 26.IX.2010, fr., I.R. Oliveira et al. 105 (VIES, SAMES); ao lado da estrada, em direção à Ponte do Parajú, 11.VII.2004, fr., L.S. Leoni et al. 5929 (VIES). Santa Maria de Jetibá, Córrego do Ouro, propriedade privada que pertence a família Berger, R.R. Santos (MBML 43547). Santa Teresa, Aparecidinha, 9.XI.1998, fr., L. Kollmann 895 (MBML); Estação Biológica Caixa D’Água, 22.IX.1998, fr., L. Kollmann 588 (MBML); 30.XI.1999, fr., V. Demuner 268 (MBML); Estação Biológica de Santa Lúcia, 18.VII.1993, est., L.D. Thomaz 887 (MBML); 31.VIII.1993, L.D. Thomaz 886 (MBML); 28.I.2016, est., W.O. Souza 491, 492 (MBML;VIES).

Micropholis crassipedicellata é endêmica do Brasil, possui distribuição conhecida, restrita ao Domínio da Mata Atlântica, com ocorrência na região Sudeste e Bahia (BFG 2015). No $\mathrm{ES}$, a espécie foi encontrada tanto em restinga do norte, quanto em regiões montanhosas e de tabuleiro de norte a sul do estado (Fig. 3), sendo aqui categorizada como pouco preocupante (LC). Floração entre os meses de Dezembro e Fevereiro, e frutificação entre Julho e Novembro.

É uma espécie pouco confundida entre as espécies ocorrentes no ES, por apresentar ramos 
e folhas estrigosas a glabrescentes, por suas folhas serem na maioria das vezes obovadas, por apresentar nervuras secundárias espaçadas entre si, distinguíveis das terciárias e ordens superiores a olho nu na face abaxial, pela nervura coletora distinta da nervura marginal e pela margem levemente revoluta.

\section{Micropholis gardneriana (A. DC.) Pierre, Not.} bot. 39. 1891.

Figs. 1m-r; 3; 5a

Árvores até $20 \mathrm{~m}$ alt. Ramos jovens raramente costados, pubescentes, tricomas ferrugíneos, lenticelas ausentes. Folhas 4-13 × 1,7-6 cm, oblongas, elípticas a obovadas, alterno-dísticas a espiraladas, discolores a concolores, cartáceas, base cuneada a obtusa, ápice acuminado, face adaxial glabra, face abaxial pubescente na nervura central e lâmina glabrescente, tricomas ferrugíneos, venação broquidódroma, nervura central sulcada na face adaxial, nervuras secundárias muito próximas, paralelas entre si com aspecto estriado, indistinguíveis das terciárias e ordens superiores a olho nu em ambas as faces, nervura coletora presente, quase fusionada com a nervura marginal, margem plana; pecíolos 4-14 mm compr., canaliculado, não costados, pubescente em folhas jovens, tricomas ferrugíneos. Fascículos 2-6-floros, axilares ou ramifloros, não estipitados. Flores uni ou bissexuadas, pedicelo 2,5-7 $\mathrm{mm}$ compr., pubescentes, tricomas ferrugíneos. Sépalas 5, 2,54,5 × 2,5-3,1 mm, ovadas, ápice obtuso a cuneado, face externa pubescente, ferrugíneos, face interna estrigosa nas duas sépalas mais externas e glabras nas três mais internas, margens não ciliadas. Pétalas 5, tubo 2-2,5 mm compr., lobos 1-1,5 × 1-1,2 mm, ovadas, ápice obtuso, glabros. Estames 5, filetes $0,2-0,5 \mathrm{~mm}$ compr., anteras $0,7-0,8 \mathrm{~mm}$ compr. Estaminódios 5, 1-1,2 mm compr., petaloides e não petaloides, glabros. Ovário 5-locular, 1,2-3 $\mathrm{mm}$ compr., ovoide a globoide, piloso, formando um arco de tricomas na base do base do ovário, tricomas ferrugíneos, arco enegrecido acima da porção mediana do ovário; estilete $0,9-2 \mathrm{~mm}$ compr., não costado, glabro; estigma 5-lobado. Frutos $0,7-1,7 \mathrm{~cm}$ compr., elipsoide a ovoide, glabrescente com tricomas resquiciais no ápice $\mathrm{e}$ na base, marrom a vináceos. Semente lisa, lustrosa, 0,6-1,3 cm compr., castanho a amarronzada; cicatriz $0,5-1,3 \times 0,7-0,8 \mathrm{~cm}$, fosca.

Material examinado: Água Doce do Norte, Mata anterior ao afloramento da torre, 24.VI.2015, est., B.G. Sossai et al. 40 (VIES); trilha da torre da Vivo, borda de Mata, 25.IX.2014, fr., A. Alves-Araújo et al. 1701 (VIES).
Ibitirama, propriedade particular de Alcindo Luis Mota Filho, a $5 \mathrm{~km}$ da entrada do município de Ibitirama, 26.X.2012, fr., T.B. Flores 1599 (MBML). Linhares, Reserva Natural Vale, 20.I.1994, fl., D.A. Folli 2184 (VIES, CVRD); 6.IV.1994, fr., D.A. Folli 2274 (VIES, CVRD); 12.II.1980, I.A. Silva 147 (CVRD); 10.II.1998, fl., D.A. Folli 3116 (CVRD); 8.II.2007, fl., J.R. Stehmann 4799 (CVRD); 14.X.2015, fl., W.O. Souza 474 (VIES). Pancas, Monumento Natural dos Pontões Capixabas, Pedra do Camelo, 8.VII.2015, fl., B.G. Sossai et al. 51 (VIES). Rio Bananal, Alto Bananal, propriedade Jonas Graci, 25.IV.2007, fr., V. Demuner 3814 (MBML). Santa Teresa, Estação Biológica de Santa Lúcia, 8.X.1990, fr., S.V. Pereira 21 (MBML); 13.IV.1993, fl., L.D. Thomaz 919 (MBML). Sooretama, Reserva Biológica de Sooretama, 17.XI.2015, fl., W.O. Souza et al. 488 (VIES).

M. gardneriana distribui-se na Colômbia, Venezuela e Brasil. No Brasil é registrada para os domínios da Amazônia, da Caatinga, do Cerrado e da Mata Atlântica (BFG 2015). No ES, distribui-se desde floresta de tabuleiro no norte à ambientes montanhosos (Fig. 3), sendo aqui categorizada como pouco preocupante (LC). Floração e frutificação em um longo período, florescendo entre Outubro a Julho, e frutificando entre Março a Outubro.

Pode ser facilmente confundida com $M$. compta (ver diferenças nos comentários de M. compta). Amostras determinadas como Micropholis gardneriana podem apresentar dois morfotipos de estaminódios: os petaloides e os não-petaloides. Nas flores femininas podem ser encontrados estames desprovidos de anteras ou bastante rudimentares, correspondendo a flores com 10 estaminódios (cinco de cada morfotipo). Essa característica não está descrita na literatura para M. compta.

4. Micropholis guyanensis (A. DC.) Pierre subsp. guyanensis, Not. Bot. 2: 40. 1891.

Figs. 2a-i; 4; 5c

Árvores até $20 \mathrm{~m}$ alt. Ramos jovens levemente costados, puberulentos, tricomas ferrugíneos, lenticelas ausentes. Folhas 5,9-15 × 2,6-5,9 cm, oblongas a elípticas, alterno-dísticas a espiraladas, discolores, coriáceas, base cuneada a levemente atenuada, ápice acuminado a cuspidado, face adaxial glabrescente, face abaxial puberulenta com margem pubescente, tricomas ferrugíneos, venação broquidódroma, nervura central levemente sulcada na face adaxial, nervuras intersecundárias podendo ser confundidas com as secundárias, nervuras secundárias distinguíveis das terciárias e ordens superiores a olho nu na face abaxial, sem aspecto 


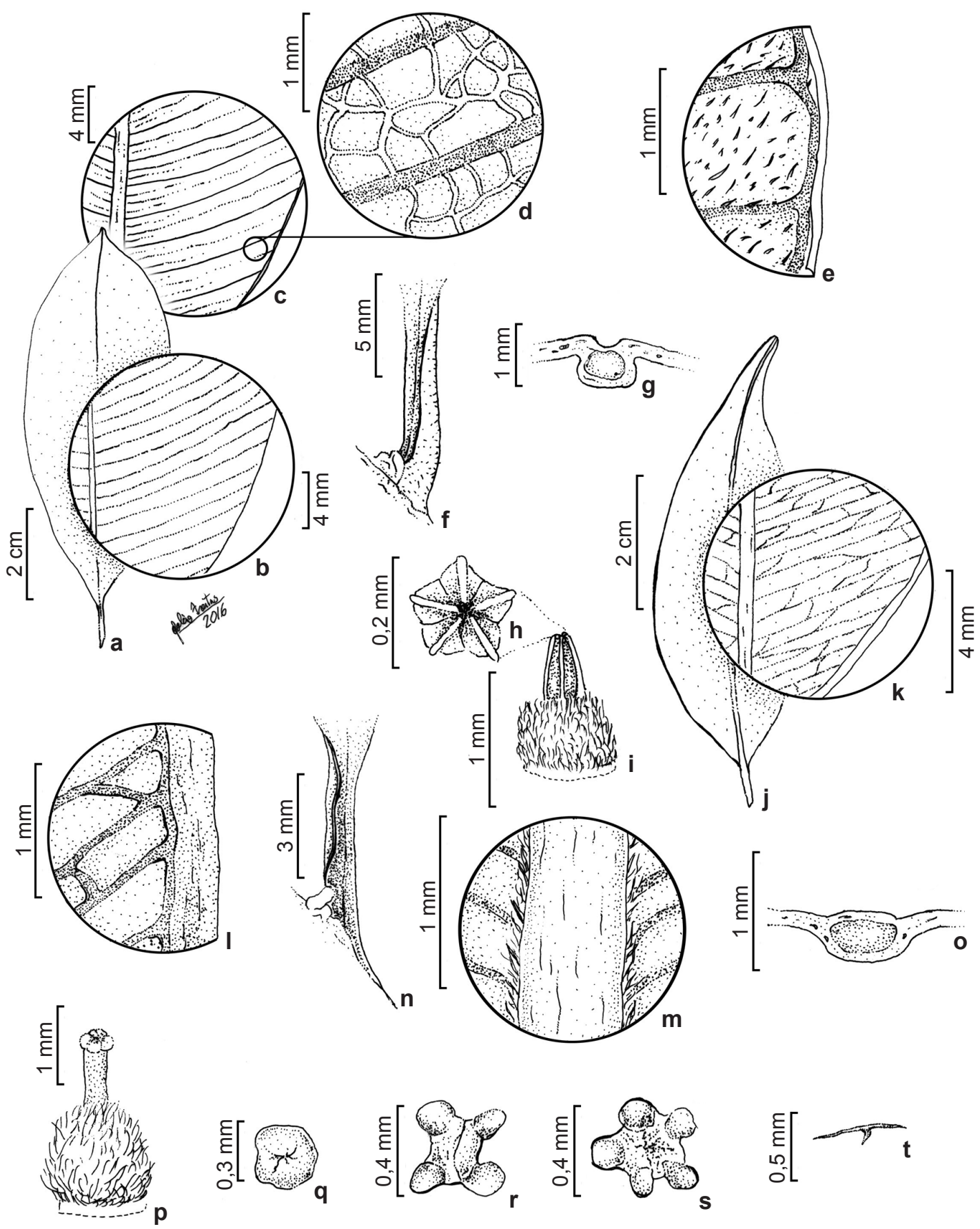

Figura 2 - a-i. Micropholis guyanensis subsp. guyanensis - a. folha; $b$. face adaxial; c. face abaxial; d. detalhe das nervuras secundárias e aréolas; e. detalhe das nervuras coletora e marginal; f. detalhe do pecíolo; g. detalhe da nervura central; h. detalhe estigma; i. ovário. $\mathrm{j}$-s. Micropholis venulosa $-\mathrm{j}$. folha; $\mathrm{k}$. face adaxial; 1 . detalhe das nervuras coletora e marginal; $\mathrm{m}$. detalhe da nervura central na face abaxial; $n$. detalhe do pecíolo; o. detalhe da nervura central; $p$. ovário; q. detalhe do estigma simples; $r$. detalhe do estigma 4-lobado; s. detalhe do estigma 5-lobado. t. tricoma malpiguiaceo que ocorre em todas as espécies. (a-i. O.J. Pereira 6893 \& L. Kollmann 7847; j-s. Kollmann 4714 \& F.Z. Saiter 332).

Figure 2 - a-i. Micropholis guyanensis subsp. guyanensis - a. leaf; b. upper surface; c. lower surface; d. detail secondary veins and areole; e. detail collecting and marginal veins; f. petiole detail; g. midrib detail; h. style detail; i. ovary. j-s. Micropholis venulosa - j. leaf; k. upper surface; l. detail collecting and marginal veins; $m$. detail midrib in upper surface; $n$. petiole detail; o. midrib detail; $p$. ovary; q. style simple detail; r. detail style 4-lobed; $\mathrm{s}$. detail style 5-lobed. t. hair malpighiaceous that occurs in all species. (a-i. O.J. Pereira 6893 \& L. Kollmann 7847;j-s. Kollmann 4714 \& F.Z. Saiter 332). 
estriado, presença de aréola entre as secundárias, nervura coletora presente, distinta da nervura marginal (bem espaçadas), margem levemente revoluta; pecíolos 8-14 mm compr., canaliculados, costados, puberulentos, tricomas ferrugíneos. Fascículos 3-11-floros, axilares, estipitados. Flores uni ou bissexuadas, pedicelo $1-3 \mathrm{~mm}$ compr., pubérulos, tricomas ferrugíneos. Sépalas $5,1,3-2,5 \times 1,2-2,3 \mathrm{~mm}$, ovadas a deltoides, ápice cuneado, obtuso a arredondado, face externa puberulenta, tricomas ferrugíneos, face interna finamente pubérulo com tricomas castanho claro, margem ciliada nas três mais internas. Pétalas 5, tubo $0,8-1,3 \mathrm{~mm}$ compr., lobos $0,4-1 \times 0,6-1 \mathrm{~mm}$, ovadas a oblongas, ápice obtuso a arredondado, glabras. Estames 5, filetes ca. 0,1 mm compr., anteras $0,4-0,6 \mathrm{~mm}$ compr. Estaminódios 5, 0,3-0,7 $\mathrm{mm}$ compr., petaloides e não petaloides, glabros. Ovário 5-locular, 0,6-1,3 mm compr., ovoide a subgloboso, piloso com tricomas formando um arco na base, tricomas ferrugíneos; estilete $0,3-1,5$ mm compr., costado, glabro; estigma 5-lobado. Pistilódio 0,7-1 mm compr.; estilete $0,3-0,5 \mathrm{~mm}$ compr. Frutos 1,5 $\times 1,3 \mathrm{~cm}$, ovoide a globoso, marrons. Semente $1,4 \times 0,8 \mathrm{~cm}$, lisa, castanho escuro; cicatriz 1,2 cm compr., fosca.

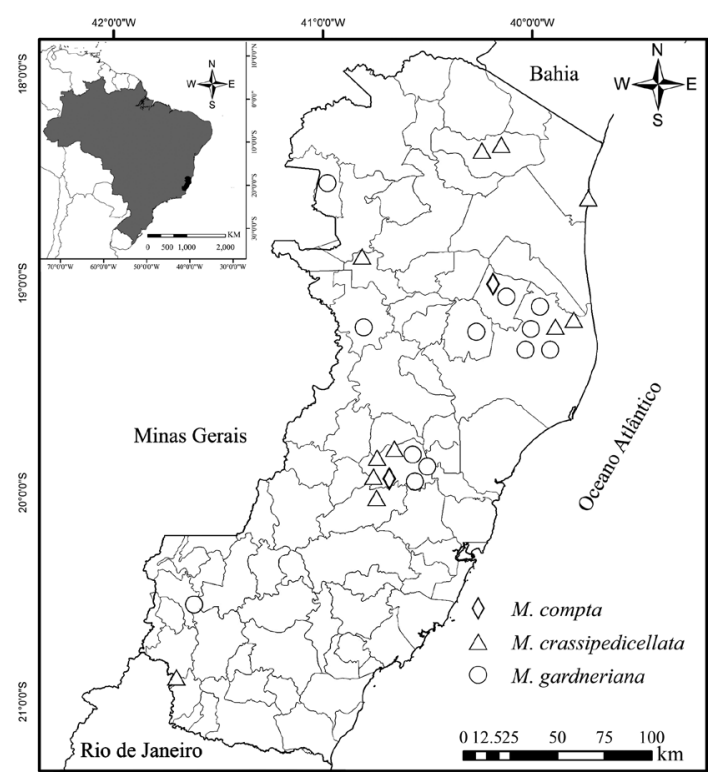

Figura 3-Mapa de distribuição geográfica de Micropholis compta, Micropholis crassipedicellata,e Micropholis gardneriana no Espírito Santo, Brasil.

Figure 3 - Distribution map of Micropholis compta, Micropholis crassipedicellata, and Micropholis gardneriana in the Espírito Santo, Brasil.
Material examinado: Domingos Martins, Floresta ciliar, Rio Jucu, 15.III.2001, fl., O.J. Pereira 6893 (VIES). Governador Lindemberg, Alto Moacir, propriedade Vitório Salomão, 21.II.2006, fl., L.F.S. Magnago 698 (MBML). Santa Maria de Jetibá, Sítio Jetibá, 26.II.2003, H.Q.B. Fernandes 3289 (MBML); Caramuru, 30.IV.2003, fl., L. Kollmann 6152 (MBML). Santa Teresa, Estação Biológica de Santa Lúcia, 17.XI.1990, fr., S.V. Pereira 34 (MBML); 1.I.1993, fl., L.D. Thomaz (MBML 9858); 13.V.1993, est., L.D. Thomaz 924 (MBML); 18.V.1993, fl., L.D. Thomaz 925 (MBML); 25.V.1993, fl., L.D. Thomaz 926 (MBML); 17.VI.2005, fl., L. Kollmann 7847 (MBML); 2.VII.2005, F.Z. Saiter 207 (MBML); Santo Antônio, 9.II.1999, fl., L. Kollmann 1857 (MBML); 16.III.1999, fl., L. Kollmann 2168 (MBML); 22.III.1999, fl., L. Kollmann 2204 (MBML); 27.IV.1999, fl., L. Kollmann 2512 (MBML).

Distribui-se desde o Sul da América Central, Caribe até a América do Sul, com exceção da Argentina, Chile, Paraguai e Uruguai. No Brasil, a espécie é registrada nos domínios da Amazônia, do Cerrado e da Mata Atlântica (BA e ES) (BFG 2015). No ES, Micropholis guyanensis subsp. guyanensis foi encontrada tanto em ambientes preservados como alterados, estando amplamente distribuída nos ambientes montanhosos da região serrana (Fig. 4), sendo aqui categorizada como pouco preocupante (LC). Período de floração entre

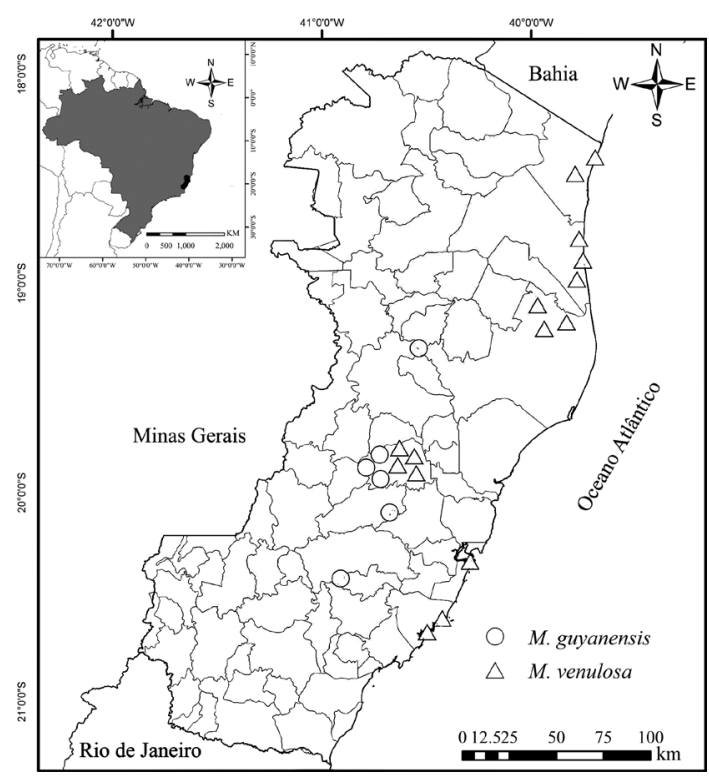

Figura 4 - Mapa de distribuição geográfica de Micropholis guyanensis e Micropholis venulosa no Espírito Santo, Brasil.

Figure 4 - Distribution map of Micropholis guyanensis and Micropholis venulosa in the Espírito Santo, Brasil. 
Janeiro e Maio, e frutificação em Novembro. Pode ser reconhecida entre as espécies ocorrentes no ES, principalmente pela coloração ferrugínea na face abaxial das folhas, além da presença de estípite nos ramos (Pennington 2006; BFG 2015).
As flores unissexuadas femininas apresentam dois morfotipos de estaminódios: os petaloides e os não-petaloides. Os não-petaloides são estames desprovidos de anteras ou bastante rudimentares. Desta forma, as flores femininas apresentam 10
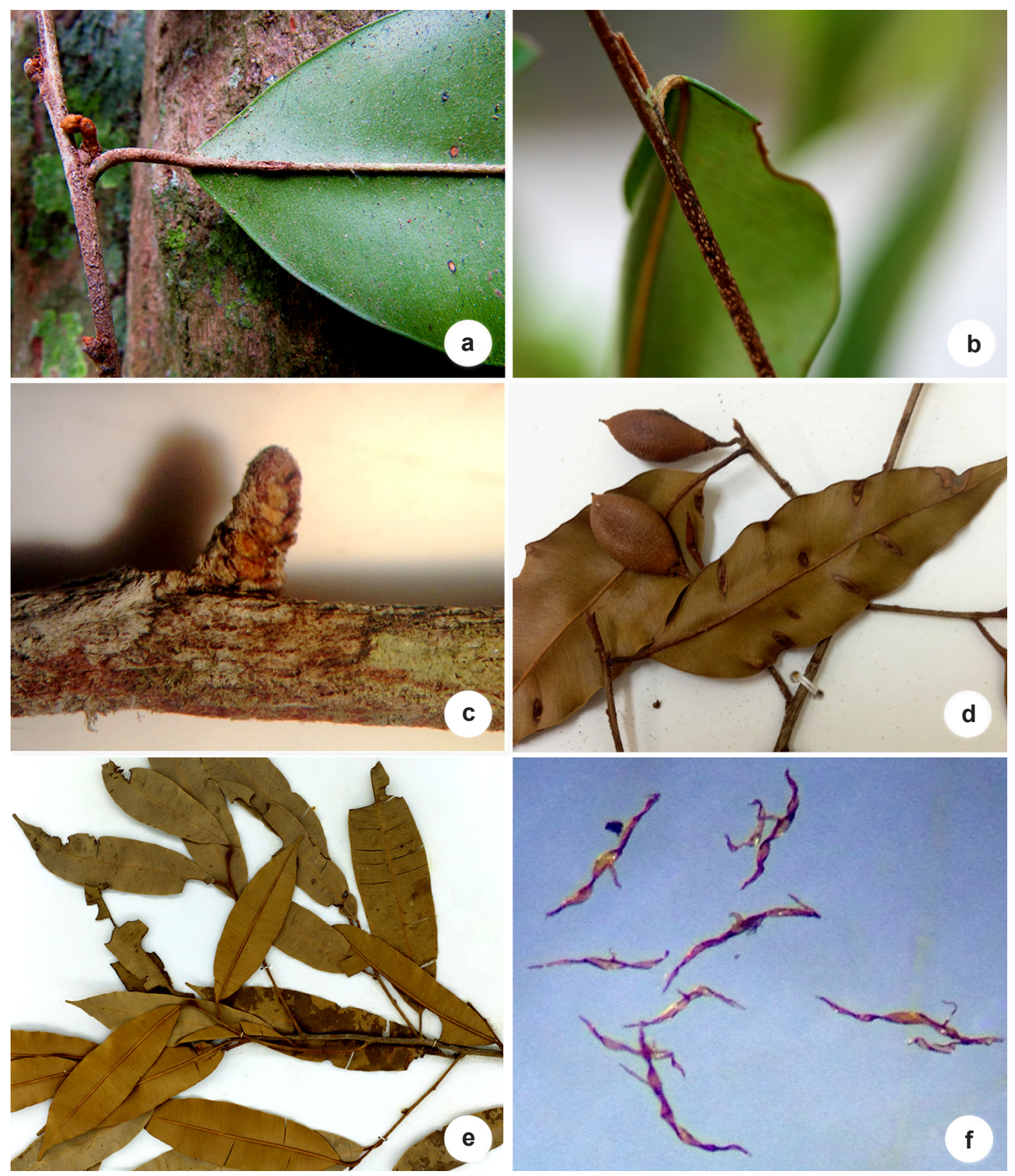

Figura 5 - a-f. Micropholis - a. Micropholis gardneriana - detalhe da folha na face abaxial; b. Micropholis crassipedicellata - detalhe do ramo com lenticelas; c. Micropholis guyanensis - detalhe do ramo com estípite; d. Micropholis venulosa - detalhe da folha e fruto; e. Micropholis compta - folhas; f. tricomas malpiguiáceos.

Figure 5 - a-f. Micropholis - a. Micropholis gardneriana - detail leaf in lower surface; b. Micropholis crassipedicellata - detail branches lenticellate; c. Micropholis guyanensis - detail branches estípite; d. Micropholis venulosa-leaf and fruit detail; e. Micropholis compta - leaf; f. malpighiaceous hair. 
estaminódios (cinco de cada morfotipo). No caso de flores masculinas é constatada a presença de um pistilódio.

5. Micropholis venulosa (Mart. \& Eichler) Pierre, Not. Bot. 2: 40. 1891.

Figs. 2j-s; 4; $5 \mathrm{~d}$

Árvores até $28 \mathrm{~m}$ alt. Ramos jovens não costados, pubescentes, tricomas marrons-dourados, lenticelas ausentes. Folhas 2,7-9 × 1-2,9 cm, elípticas a lanceoladas, alterno-dísticas, discolores a concolores, cartáceas a coriáceas, base cuneada, ápice atenuado a levemente acuminado, face adaxial glabra, face abaxial pubescente na nervura central e lâmina glabra em folhas jovens, tricomas marrom-ferruginosos, venação broquidódroma, nervura central plana a levemente proeminente na face adaxial, nervuras secundárias muito próximas, paralelas entre si com aspecto estriado, indistinguíveis das terciárias e ordens superiores a olho nu em ambas as faces, nervura coletora presente, quase fusionada à nervura marginal, margem plana; pecíolos 2-7 mm compr., levemente canaliculado, não costados, pubescente em folhas jovens, tricomas marrom-ferruginosos. Fascículos 3-6-floros, axilares, não estipitados. Flores uni ou bissexuadas, pedicelo 3-7 $\mathrm{mm}$ compr., pubescentes, tricomas marrom-ferruginosos; Sépalas 4-5, 1,2-2 × 1,1-2 mm, ovadas, ápice obtuso, face externa pubescente, tricomas marromdourados, face interna estrigoso, tricomas alvos, margem não ciliada. Pétalas 4-5, tubo 0,3-0,8 mm compr., lobos 0,4-0,9 × 0,4-1 mm, ovadas, ápice obtuso, glabros. Estames 4-5, filetes 0,1-0,2 mm compr., antera 0,2-0,6 mm compr. Estaminódios 4-5, 0,5-0,8 mm compr., petaloides ou não, glabros. Ovário 4-5-locular, 0,5-0,9 mm compr., ovoide, piloso formando um arco de tricomas marrom-ferrugíneos na base; estilete $0,4-0,5 \mathrm{~mm}$ compr., não costado, glabro; estigma 4-5-lobado a simples. Frutos $0,6-2,7 \times 1-1,1 \mathrm{~cm}$, elipsoide, ovoide a globoso, glabro a glabrescente nos frutos mais jovens, castanho a marrom. Semente 1,2-2,1 $\times 0,8 \mathrm{~cm}$, lisa, lustrosa, castanho escuro a marrom, achatada longitudinalmente na cicatriz; cicatriz $1,2-2 \times 0,1-0,3 \mathrm{~cm}$, fosca.

Material examinado: Conceição da Barra, Parque Estadual de Itaúnas, 31.I.2012, fr., A.O. Giaretta 1217 (VIES); 7.XII.2011, fl., A.O. Giaretta 1125 (VIES). Guarapari, Parque Estadual Paulo César Vinha, 4.I.2000, fl., A.M. Assis 766 (VIES); 15.V.1992, fr., L.C. Fabris 857 (VIES); 14.XI.2008, fl., L.C. Fabris 871 (VIES); Setiba, 5.X.1992, fl., L.C. Fabris 711 (VIES); 23.VII.1992, fr., L.C. Fabris 813 (VIES). Linhares, Reserva Natural Vale, 26.X.1979, fl., I.A. Silva 105 (CVRD); 10.II.1994, fl.,
D.A. Folli 2208 (CVRD, VIES); 27.X.1994, fr., D.A. Folli 2411 (CVRD, VIES); 13.XII.1997, f1., M. Simonelli 888 (CVRD); Restinga de Comboios, 23.I.2013, fr., L.F.T. Menezes 2082 (VIES). Santa Teresa, Parque Natural Municipal de São Lourenço, 24.V.2003, fl., T.A. Cruz 62 (MBML); Santo Antônio, 26.X.1999, fr., V. Demuner 149 (MBML); Estação Biológica de Nova Lombardia, 26.X.1989, fl. e fr., J.P. Souza (VIES 4705); Estação Biológica de Santa Lúcia, 18.VIII.1993, fr., L.D. Thomaz 891 (MBML); 3.III.1993, fl. e fr., L.D. Thomaz 890 (MBML); 5.XI.2009, fl., F.Z. Saiter 332 (MBML); Reserva Biológica Augusto Ruschi, 25.IX.2001, fr., L. Kollmann 4714 (MBML); 16.VII.2002, fr., R.R. Vervloet 463 (MBML); 27.III.2003, fl., R.R. Vervloet 2078 (MBML). São Mateus, Bairro Liberdade, 6.III.2009, fl., O.J. Pereira et al. 7617 (VIES); 29.IX.2007, fr., M.B. Faria 84 (VIES); 27.IX.2008, fr., A.O. Giaretta 340 (VIES); 28.II.2012, fr., A.O. Giaretta 1247 (VIES); 15.IX.2006, fr., L.F.T. Menezes 1541 (VIES); 27.II.2007, fr., M.B. Faria 16 (VIES); 17.VIII.2008, fr., M.M. Monteiro 42 (VIES); 6.II.2010, fr., M.M. Monteiro 193 (VIES). Vila Velha, Fazenda Itapuera, 1.VII.1980, fl. e fr., B. Weinberg (MBML 6426);

M. venulosa distribui-se desde a Costa Rica, Panamá até a América do Sul. No Brasil, a espécie é registrada nos domínios da Amazônia, do Cerrado e da Mata Atlântica (ES, MG e provável ocorrência em SP) (BFG 2015). Já no ES, a espécie é encontrada em florestas de tabuleiro do norte, ambientes montanhosos na região serrana e em restingas de norte a sul do estado (Fig. 4), sendo aqui categorizada como pouco preocupante (LC). Período de floração e frutificação ao longo de todo o ano.

Esta espécie também apresenta dois tipos de estaminódios (petaloides e não-petaloides). No caso de flores femininas, encontram-se estames desprovidos de anteras ou bastante rudimentares, correspondendo a flores com 8-10 estaminódios (4-5 de cada morfotipo). É distinta das demais espécies, principalmente, por suas folhas com 2,7-9 $\times 1-2,9 \mathrm{~cm}$, elípticas a lanceoladas, e com filotaxia alterno-dísticas (Pennington 2006; BFG 2015).

\section{Agradecimentos}

Agradecemos aos curadores e técnicos dos herbários CVRD, MBML, SAMES e VIES; aos Msc. Jaquelini Luber e Joelcio Freitas, a confecção dos mapas e ilustrações; à UFES/CEUNES, toda a infraestrutura necessária para coletas e análises; a toda equipe do Laboratório $\mathrm{SGV}$, o apoio e companheirismo; à CAPES, a concessão da bolsa de Mestrado da primeira autora; à FAPES - Fundação de Amparo à Pesquisa e Inovação do Espírito Santo, o financiamento do Projeto 
Sapotaceae no Espírito Santo (Edital 06/2014 Universal Individual. Processo no 67652000).

\section{Referências}

Alves-Araújo A \& Alves M (2010) Flora da Usina São José, Igarassu, Pernambuco: Sapotaceae. Rodriguésia 61: 303-318.

Bachman S, Moat J, Hill A, de la Torre J \& Scott B (2011) Supporting red list threat assessments with GeoCAT: Geospatial Conservation Assessment Tool. Zookeys 150: 117-126.

BFG - The Brazil Flora Group (2015) Growing knowledge: an overview of seed plant diversity in Brazil. Rodriguésia 66: 1085-1113.

Bridson D \& Forman L (1998) The Herbarium handbook. Royal Botanical Garden, Lubrecht \& Cramer Ltd., Richmond. 348p.

CNCFlora (2017) Centro Nacional de Conservação da Flora. Disponível em <http://cncflora.jbrj.gov.br/ portal/pt-br/listavermelha/SAPOTACEAE $>$. Acesso em 5 agosto 2017.

Dutra VF, Alves-Araújo A \& Carrijo TT (2015) Angiosperm checklist of Espírito Santo: using electronic tools to improve the knowledge of an Atlantic Forest biodiversity hotspot. Rodriguésia 66: 1145-1152.

Garbin ML, Saiter FZ, Carrijo TT \& Peixoto AL (2017) Breve histórico e classificação da vegetação capixaba. Rodriguésia 68: 1883-1894.

Harris JG \& Harris MW (2001) Plant identification terminology and illustrated glossary. $2^{\text {nd }}$ ed. Spring Lake Publishing, Spring Lake. 216p.

Hickey LJ (1973) Classification of the architecture of dicotyledonous leaves. American Journal of Botany 1: 17-33.

IBGE - Instituto Brasileiro de Geografia e Estatística (2004) Mapa da vegetação do Brasil. Disponível em <http://www.ibge.gov.br/home/presidencia/ noticias/21052004biomas.shtm $>$. Acesso em 14 outubro 2016.

IPEMA - Instituto de Pesquisas da Mata Atlântica (2005) Conservação da Mata Atlântica no estado do Espírito Santo: cobertura florestal e unidades de conservação. IPEMA, Vitória. 142p.

IUCN - International Union for Conservation of Nature (2017) IUCN Red List of Threatened Species.
Disponível em <http://www.iucnredlist.org/>. Acesso em 14 abril 2017.

Pennington TD (1990) Flora Neotropica Monograph 52. Sapotaceae. The New York Botanical Gardens, New York. 770p.

Pennington TD (1991) The genera of Sapotaceae. Royal Botanical Garden, Kew. 295p.

Pennington TD (2004) Sapotaceae (Sapodilla family). In: Smith N, Mori SA, Henderson A, Stevenson DW \& Heald SV (eds.) Flowering plants of the Neotropics. Princeton University Press, New Jersey. Pp. 342-344.

Pennington TD (2006) Flora da Reserva Ducke, Amazonas, Brasil: Sapotaceae. Rodriguésia 57: 251-366.

Silva SS (2004) Contribuição ao estudo morfo-anatômico de espécies de Micropholis (Griseb.) Pierre (Sapotaceae. Juss.) no estado do Pará. Dissertação de Mestrado. Universidade Federal Rural da Amazônia, Belém. 114p.

SOS Mata Atlântica - Fundação SOS Mata Atlântica \& INPE - Instituto Nacional de Pesquisas Espaciais (2011) Atlas dos remanescentes florestais da Mata Atlântica período 2008-2010. Fundação SOS Mata Atlântica e INPE, São Paulo. 120p.

Swenson U \& Anderberg AA (2005) Phylogeny, character evolution, and classification of Sapotaceae (Ericales). Cladistics 21: 101-130.

Swenson U, Richardson JE \& Bartish IV (2008) Multigene phylogeny of the pantropical subfamily Chrysophylloideae (Sapotaceae): evidence of generic polyphyly and extensive morphological homoplasy. Cladistics 24: 1006-1031.

Terra-Araújo MH, Faria AD, Ribeiro JELS \& Swenson U (2012) Flower biology and subspecies concepts in Micropholis guyanensis (Sapotaceae): evidence of ephemeral flowers in the family. Australian Systematic Botany 25: 295-303.

Thiers B [continuamente atualizado]. Index Herbariorum: a global directory of public herbaria and associated staff. New York Botanical Garden's Virtual Herbarium. Disponível em $<$ http://sweetgum.nybg. org/science/ih/>. Acesso em 12 setembro 2016.

Thomaz LD (2010) A Mata Atlântica no estado do Espírito Santo, Brasil: de Vasco Fernandes Coutinho ao século 21. Boletim do Museu de Biologia Mello Leitão 27: 5-20. 